\title{
RESEARCH
}

Open Access

\section{The impact of telephone follow up on adverse events for Aboriginal people with chronic disease in new South Wales, Australia: a retrospective cohort study}

Amanda Jayakody ${ }^{1,2,34^{*}+}$ (D) Erin Passmore ${ }^{4 \dagger}$, Christopher Oldmeadow ${ }^{5,6}$, Jamie Bryant ${ }^{1,2,3}$, Mariko Carey ${ }^{1,2,3}$, Eunice Simons ${ }^{7}$, Aaron Cashmore ${ }^{4,8}$, Louise Maher ${ }^{4}$, Kiel Hennessey ${ }^{7}$, Jacinta Bunfield ${ }^{9}$, Maurice Terare ${ }^{9}$, Andrew Milat ${ }^{4,10}$ and Rob Sanson-Fisher ${ }^{1,2,3}$

\begin{abstract}
Background: Chronic diseases are more prevalent and occur at a much younger age in Aboriginal people in Australia compared with non-Aboriginal people. Aboriginal people also have higher rates of unplanned hospital readmissions and emergency department presentations. There is a paucity of research on the effectiveness of follow up programs after discharge from hospital in Aboriginal populations. This study aimed to assess the impact of a telephone follow up program, 48 Hour Follow Up, on rates of unplanned hospital readmissions, unplanned emergency department presentations and mortality within 28 days of discharge among Aboriginal people with chronic disease.

Methods: A retrospective cohort of eligible Aboriginal people with chronic diseases was obtained through linkage of routinely-collected health datasets for the period May 2009 to December 2014. The primary outcome was unplanned hospital readmissions within 28 days of separation from any acute New South Wales public hospital. Secondary outcomes were mortality, unplanned emergency department presentations, and at least one adverse event (unplanned hospital readmission, unplanned emergency department presentation or mortality) within 28 days of separation. Logistic regression models were used to assess outcomes among Aboriginal patients who received 48 Hour Follow Up compared with eligible Aboriginal patients who did not receive 48 Hour Follow Up.

Results: The final study cohort included 18,659 patients with 49,721 separations, of which 8469 separations (17.0, 95\% confidence interval (Cl): 16.7-17.4) were recorded as having received 48 Hour Follow Up. After adjusting for potential confounders, there were no significant differences in rates of unplanned readmission or mortality within 28 days between people who received or did not receive 48 Hour Follow Up. Conversely, the odds of an unplanned emergency department presentation (Odds ratio $(\mathrm{OR})=0.92 ; 95 \% \mathrm{Cl}: 0.85,0.99 ; P=0.0312$ ) and at least one adverse event $(\mathrm{OR}=0.91 ; 95 \% \mathrm{Cl}: 0.85,0.98 ; P=0.0136)$ within 28 days were significantly lower for separations where the patient received 48 Hour Follow Up compared with those that did not receive follow up.

(Continued on next page)
\end{abstract}

\footnotetext{
*Correspondence: amanda.jayakody@uon.edu.au

${ }^{+}$Amanda Jayakody and Erin Passmore contributed equally to this work. ${ }^{1}$ Health Behaviour Research Collaborative, School of Medicine and Public Health, Faculty of Health and Medicine, University of Newcastle, Callaghan, NSW 2308, Australia

${ }^{2}$ Priority Research Centre for Health Behaviour, University of Newcastle,

Callaghan 2308, NSW, Australia

Full list of author information is available at the end of the article
}

(c) The Author(s). 2018 Open Access This article is distributed under the terms of the Creative Commons Attribution 4.0 International License (http://creativecommons.org/licenses/by/4.0/), which permits unrestricted use, distribution, and reproduction in any medium, provided you give appropriate credit to the original author(s) and the source, provide a link to the Creative Commons license, and indicate if changes were made. The Creative Commons Public Domain Dedication waiver (http://creativecommons.org/publicdomain/zero/1.0/) applies to the data made available in this article, unless otherwise stated. 
(Continued from previous page)

Conclusions: Receipt of 48 Hour Follow Up was associated with both a reduction in emergency department presentations and at least one adverse event within 28 days of discharge, suggesting there may be merit in providing post-discharge telephone follow up to Aboriginal people with chronic disease.

Keywords: Unplanned readmission, Telephone follow up, Aboriginal health, Health services research

\section{Background}

Aboriginal and Torres Strait Islander people in Australia (hereafter 'Aboriginal people') experience considerably poorer health outcomes compared with non-Aboriginal people, and also compared with other Indigenous people in New Zealand, Canada and the United States [1]. In Australia, Aboriginal men, on average, live 10.6 years less than non-Aboriginal men, while Aboriginal women, on average, live 9.5 years less than non-Aboriginal women [2] .This difference is largely accounted for by chronic diseases such as cardiovascular diseases, type 2 diabetes, chronic respiratory diseases and renal diseases, which are more prevalent among Aboriginal people and occur at a much younger age [3, 4].

Aboriginal people also have higher rates of unplanned hospital readmissions and emergency department (ED) presentations. In New South Wales (NSW), Australia, Aboriginal people are 1.3 times more likely to have an unplanned hospital readmission within 28 days of discharge from hospital, and 1.3 times more likely to re-present to the ED within $48 \mathrm{~h}$ compared with non-Aboriginal people [5]. These higher hospital utilisation rates may indicate the health needs of Aboriginal people are not being met during their hospital stay and post-discharge.

Telephone follow up (TFU) is a strategy that has been frequently used to support patients after discharge from hospital. TFU involves a hospital or community health professional telephoning a discharged patient at home to provide ongoing education and management of symptoms with the aim of reducing problems post-discharge [6]. Systematic reviews have highlighted that TFU is a common part of successful multi-component interventions in reducing readmissions in general medical and surgical patients $[7,8]$. A systematic review by Jayakody and colleagues examined 10 interventions utilising TFU in combination with other strategies amongst patients with chronic disease [9]. Of the 10 studies identified, five were found to be effective in reducing unplanned readmission within 30 days of discharge. Interventions that were effective included three studies which provided TFU in addition to pre-discharge support; and two studies which provided TFU with both pre- and post-discharge support such as education, discharge planning, and home visits [9]. Despite a developing evidence base for the effectiveness of TFU in reducing unplanned hospital readmissions, no studies have examined the effectiveness of TFU in Aboriginal populations, either in Australia or elsewhere.

The 48 Hour Follow Up program is a NSW Health state government initiative to improve coordination and management of care for Aboriginal people with chronic diseases. The program aims to reduce unplanned hospital readmissions and improve health outcomes for Aboriginal people with a chronic disease. The program involves identifying, from hospital records, Aboriginal people meeting the following eligibility criteria: 1) Aboriginal and/or Torres Strait Islander person; 2) aged 15 years and older; 3) admitted to an acute care facility; and 4) has a chronic disease. An attempted telephone call is made to the identified eligible patient within two working days of discharge from an acute care facility. The phone call is ideally conducted by an Aboriginal health professional but in some cases a non-Aboriginal staff member may make the call. The call covers, at a minimum: access to medications; whether the patient has referrals and follow up appointments in place; and general wellbeing. The caller seeks to identify and resolve any issues with the patient's postdischarge care, and to ensure appropriate links to general practitioners, Aboriginal Community Controlled Health Services, specialists and other services that are able to assist the patient with receiving appropriate post-discharge care. The program commenced in 2009 and is currently delivered in all 15 local health districts (LHD) (government corporations responsible for managing public hospitals and providing health services to defined geographical areas of the state) in NSW.

Due to the high rates of chronic disease and unplanned hospital readmission amongst Aboriginal people, it is critical to develop evidence about what strategies are effective in reducing unplanned readmission within 28 days of discharge. This study addresses the paucity of research evidence in this field for Aboriginal populations by providing state-wide data on the impact of a telephone follow up service for Aboriginal people with chronic disease. It provides novel data to assist policy makers in determining the impact of the 48 Hour Follow Up program and determining its future directions. Furthermore, this study provides a unique evaluation of a system-level intervention which is rarely published in the literature [10, 11]. Specifically, the study aims to assess the impact of the 48 Hour Follow Up program on rates of unplanned hospital readmissions 
within 28 days of discharge among Aboriginal people with chronic disease in NSW. As a secondary aim the impact of the program on unplanned ED presentations, mortality and at least one adverse event (unplanned hospital readmission, unplanned ED presentation or mortality) within 28 days of discharge were also examined.

\section{Methods}

\section{Study design}

A retrospective cohort was obtained through linkage of routinely-collected health datasets.

\section{Data sources}

Data were obtained from the 48 Hour Follow Up Program Register, a public health register established under the NSW Public Health Act 2010 [12], comprising linked data from the following five sources:

1) 48 Hour Follow Up Program Dataset comprises records from each participating LHD for all patients identified by the LHD as eligible to receive 48 Hour Follow Up. Data includes the dates of admission and separation from hospital, unique patient identifiers and whether or not the patient received 48 Hour Follow Up;

2) NSW Admitted Patient Data Collection (APDC) comprises records of all separations in NSW private and public hospitals, including discharges, transfers and deaths;

3) NSW Register of Births, Deaths and Marriages (RBDM) provides fact of death for all deaths registered in NSW;

4) NSW Emergency Department Data Collection $(E D D C)$ comprises records of all presentations to EDs in NSW public hospitals;

5) NSW Chronic Disease Management Program (CDMP) Minimum Dataset comprises records from the NSW Health Chronic Disease Management Program, which provides care coordination and selfmanagement support to people with chronic disease. The dataset also holds information on participation in Healthways, a telephone health coaching service offered to a subset of CDMP participants (this service was offered in a number of LHDs to patients who had one unplanned hospital admission in the previous 12 months relating to one of the five chronic conditions that were part of the CDMP (i.e. diabetes, hypertension, coronary artery disease, heart failure, chronic obstructive pulmonary disease)).

\section{Study population}

\section{Eligibility criteria}

The study sample included all patients who met the eligibility criteria of the 48 Hour Follow Up Program in the period May 2009 to December 2014. Eligible patients were: 1) Aboriginal and/or Torres Strait Islander people; 2) aged 15 years and older at the time of admission; 3) admitted to an acute facility in a NSW public hospital; 4) discharged from hospital to the community; and 5) had one or more of the following ICD-10-defined chronic diseases as a principal or additional diagnosis: cardiovascular disease, diabetes, respiratory disease and renal diseases (Additional file 1). Eligible patients for this data analysis included all those identified in the 48 Hour Follow Up Program Dataset (indicating LHD staff assessed the patient as eligible for 48 Hour Follow Up), plus patients identified through the APDC as meeting the eligibility criteria for 48 Hour Follow Up.

\section{Exclusion criteria}

Patients were excluded if they were readmitted to hospital within $48 \mathrm{~h}$ of discharge, as the LHD may not have been able to follow up the patient prior to the readmission. Duplicate records were also excluded.

\section{Data linkage}

The data sources were linked by the Centre for Health Record Linkage using probabilistic record linkage methods [13]. Following linkage, disease-related, sociodemographic and admission variables (see Explanatory variables below) were derived from the APDC dataset. Any missing data were populated from the 48 Hour Follow Up Program dataset. The exception to this was Aboriginality; patients were considered an Aboriginal person if they were listed as being an Aboriginal and/or Torres Strait Islander person on any APDC record, or if they were identified in the 48 Hour Follow Up Program dataset (May 2009 to December 2014). This method was selected based on the advice of the study's advisory committee, which had Aboriginal representation. This was considered the most accurate method available for retrieving Aboriginal status. The APDC is estimated to correctly report Aboriginal status at a level of 90.7\% (95\% CI 84.6-94.2) [14]. The inclusion and exclusion criteria were then applied to give the final dataset for analysis. All data were de-identified.

\section{Analysis variables \\ Primary and secondary outcomes}

The primary outcome was unplanned hospital readmissions within 28 days of separation from any acute facility in a NSW public hospital. 'Unplanned' refers to emergency admissions where admission is required within $24 \mathrm{~h}$ of diagnosis. Readmission refers to an admission with an admission date within 28 days of the discharge date for any purpose other than mental health, chemotherapy or dialysis. Transfers from other facilities were not considered as readmissions, and excluded from analysis. Secondary outcomes were mortality within 28 days of separation; unplanned ED 
presentation within 28 days of separation ('unplanned' refers to either an 'emergency presentation' or an 'unplanned return visit for continuing condition' as reported in the EDDC); and an "adverse event" defined as mortality, unplanned ED presentation or unplanned hospital readmission within 28 days of separation.

\section{Explanatory variables}

The main explanatory variable of interest was receipt of 48 Hour Follow Up. Eligible individuals were classified as either having: 1) received 48 Hour Follow Up; or 2) not received 48 Hour Follow Up. The 48 Hour Follow Up Program Dataset reports whether the patient was followed up within two working days of discharge or outside two working days. Sensitivity analyses, conducted to examine any significant differences between the two timeframes of follow up, found results were broadly similar (results are provided in Additional file 2). Therefore, for the purpose of this analysis patients followed up both within or outside two working days were classified as having received 48 Hour Follow Up.

Based on discussions with content experts and a review of the literature the following variables were considered as potential confounders:

a) Models of care: Although all LHDs implement the 48 Hour Follow Up phone call, the model of program delivery varies. There are four primary models: 1) a centralised model, where all 48 Hour Follow Up phone calls for the LHD are conducted from a central call centre (five LHDs implement this model); 2) a shared care model, where there is close integration between hospital and communitybased services, and the most appropriate staff member conducts the phone call (three LHDs); 3) a localised model, where an Aboriginal Health Worker at each inpatient facility conducts the phone call, and sometimes also a home visit (six LHDs); and 4) an Aboriginal Medical Service (AMS)-contracted model, where the local AMS conducts calls to patients currently case-managed by the AMS, and the LHD conducts calls to non-AMS patients (one LHD).

b) Enrolment in a CDMP or a Healthways program at the date of separation.

c) Disease-related variables: Charlson Comorbidity Index [15], and the number of additional diagnoses (less than 2; 2 or more).

d) Sociodemographic variables: Patient's gender, age, marital status, and Index of Relative Socioeconomic Disadvantage (IRSD) quintile. The IRSD is a general socio-economic index that summarises a range of information about the economic and social conditions of people and households within a geographic area [16].

e) Admission variables: The following variables were collected for each hospital admission: year of admission, length of stay, and number of previous admissions within the study period.

\section{Statistical analysis}

Logistic regression models were used to assess rates of unplanned hospital readmissions, mortality, unplanned ED presentations and adverse events within 28 days of discharge among Aboriginal patients who received 48 Hour Follow Up compared with eligible Aboriginal patients who did not receive 48 Hour Follow Up. Potentially confounding variables (models of care, enrolment in a CDMP or Healthways program, Charlson Comorbidity Index, number of additional diagnoses, sociodemographic factors, year of admission, length of stay and number of previous admissions) were identified by comparing the characteristics of patients who received 48 Hour Follow Up compared with eligible patients who did not receive 48 Hour Follow Up using logistic regression models. Variables which were associated at a 5\% significance level with both receipt of 48 Hour Follow $\mathrm{Up}$ and the adverse event were included in the logistic regression models. Clustering from repeated admissions for the same patient was accounted for by using generalised estimating equations with an exchangeable correlation structure, and robust Hubert-White standard errors were used. A detailed description of this analysis is available online as part of a wider evaluation report. [17] All analyses were done using SAS 9.4 software [18].

The study was approved by the University of Newcastle Human Research Ethics Committee (H-2013-0381) and the NSW Aboriginal Health and Medical Research Council Ethics Committee (967/13).

\section{Results}

In the linked dataset there were 407,729 hospital separations for Aboriginal patients aged 15 years or older who attended a public hospital in NSW between May 2009 and December 2014. Of these, 350,954 separations which did not meet the 48 Hour Follow Up program criteria were excluded. An additional 7054 records were removed due to being duplicate records or because the separation was followed by a readmission within $48 \mathrm{~h}$. The final study cohort included 18,659 Aboriginal patients, with 49,721 separations. The mean number of separations per patient was 2.6 (Standard deviation $(\mathrm{SD})=4.5$ ).

Of the 49,721 eligible separations, 8469 (17.0\%, 95\% CI 16.7-17.4) were recorded as having received 48 Hour Follow Up. Among patients who received 48 Hour Follow Up, $73.6 \%(n=6230)$ were followed up within two working days of discharge from hospital, and the 
remaining 26.4\% $(n=2239)$ were followed up outside two working days. Table 1 presents the characteristics associated with receiving 48 Hour Follow Up, adjusted for model of care and year. Relative to the least socially disadvantaged quintile (1st quintile), all increasing quintiles of social disadvantage had higher odds of follow up (2nd quintile $\mathrm{OR}=1.44 ; 95 \% \mathrm{CI}=1.30,1.60$; 3rd quintile $\mathrm{OR}=1.37 ; 95 \% \mathrm{CI}=1.24,1.52 ;$ 4th quintile $\mathrm{OR}=1.09$; $95 \% \mathrm{CI}=0.98,1.21 ; 5$ th quintile $\mathrm{OR}=1.38 ; 95 \% \mathrm{CI}=1$. $24,1.54)$. Hospital stays of longer than one day had higher odds of being followed up compared with stays of one day or less $(\mathrm{OR}=1.28 ; 95 \% \mathrm{CI}=1.21,1.35)$. Patients with two or more diagnoses had lower odds of being followed up compared with patients with less than two diagnoses $(\mathrm{OR}=0.80 ; 95 \% \mathrm{CI}=0.75,0.86)$. Similarly, patients with a higher Charlson Comorbidity Index had lower odds of follow up $(\mathrm{OR}=0.72 ; 95 \% \mathrm{CI}=0.70,0.75)$. There was no significant association between gender, age, marital status, participation in CDMP and Healthways, and the number of previous admissions with receiving 48 Hour Follow Up.

\section{Adverse events following hospital separation}

Table 2 presents rates of adverse events within 28 days of discharge from hospital. Compared with eligible patients who did not receive 48 Hour Follow Up, patients who received 48 Hour Follow Up had lower rates of unplanned hospital readmissions, unplanned ED presentations, mortality and adverse events (unplanned readmission, unplanned ED presentation or mortality) within 28 days of discharge from hospital (Table 2).

Table 1 Characteristics associated with receiving 48 Hour Follow Up among Aboriginal patients, adjusted for model of care and year $(N=49,721)^{*}$

\begin{tabular}{|c|c|c|c|c|c|}
\hline \multirow[b]{2}{*}{ Variable } & \multirow[b]{2}{*}{ Category } & \multicolumn{2}{|l|}{$\mathrm{N}(\%)$} & \multirow[b]{2}{*}{$\mathrm{OR}(95 \% \mathrm{Cl})$} & \multirow[b]{2}{*}{$P$-value } \\
\hline & & $\begin{array}{l}\text { Not followed up } \\
(n=41,252)\end{array}$ & $\begin{array}{l}\text { Followed up } \\
(n=8469)\end{array}$ & & \\
\hline \multirow[t]{2}{*}{ Gender } & Male & $18,765(83 \%)$ & $3818(17 \%)$ & ref & 0.9040 \\
\hline & Female & $22,319(83 \%)$ & $4591(17 \%)$ & $1.00(0.94,1.07)$ & \\
\hline \multirow[t]{5}{*}{ Marital status } & Married/de facto & $15,448(84 \%)$ & $2874(16 \%)$ & ref & 0.1269 \\
\hline & Single & $13,710(84 \%)$ & $2619(16 \%)$ & $1.01(0.93,1.09)$ & \\
\hline & Widowed & $5185(86 \%)$ & $877(14 \%)$ & $1.04(0.92,1.17)$ & \\
\hline & Divorced/separated & $5672(85 \%)$ & $1014(15 \%)$ & $1.03(0.93,1.14)$ & \\
\hline & Not known & $441(92 \%)$ & $37(7.7 \%)$ & $0.63(0.44,0.90)$ & \\
\hline \multirow[t]{5}{*}{ IRSD quintile } & 1st quintile - least disadvantaged & $7098(87 \%)$ & $1087(13 \%)$ & ref & $<.0001$ \\
\hline & 2nd quintile & $7631(82 \%)$ & $1642(18 \%)$ & $1.44(1.30,1.60)$ & \\
\hline & 3rd quintile & $9039(83 \%)$ & $1809(17 \%)$ & $1.37(1.24,1.52)$ & \\
\hline & 4th quintile & $8016(86 \%)$ & $1357(14 \%)$ & $1.09(0.98,1.21)$ & \\
\hline & 5th quintile - most disadvantaged & $8671(85 \%)$ & $1484(15 \%)$ & $1.38(1.24,1.54)$ & \\
\hline \multirow[t]{2}{*}{ Participation in CDMP } & Did not participate & $40,206(83 \%)$ & $8160(17 \%)$ & ref & 0.1445 \\
\hline & Participated & $1046(77 \%)$ & $309(23 \%)$ & $1.16(0.95,1.40)$ & \\
\hline \multirow[t]{2}{*}{ Participation in Healthways } & Did not participate & $41,230(83 \%)$ & $8456(17 \%)$ & ref & 0.1270 \\
\hline & Participated & $22(63 \%)$ & $13(37 \%)$ & $1.91(0.83,4.41)$ & \\
\hline \multirow[t]{2}{*}{ Length of stay } & 1 day or less & $15,652(85 \%)$ & $2729(15 \%)$ & ref & $<.0001$ \\
\hline & More than 1 day & $24,835(84 \%)$ & $4692(16 \%)$ & $1.28(1.21,1.35)$ & \\
\hline \multirow[t]{2}{*}{ No. of previous admissions } & None & $15,269(82 \%)$ & $3390(18 \%)$ & ref & 0.3259 \\
\hline & 1 or more & $25,983(84 \%)$ & $5079(16 \%)$ & $0.97(0.92,1.03)$ & \\
\hline \multirow[t]{2}{*}{ No. of additional diagnoses } & Less than 2 & $11,118(76 \%)$ & $3526(24 \%)$ & ref & $<.0001$ \\
\hline & 2 or more & $30,134(86 \%)$ & $4943(14 \%)$ & $0.80(0.75,0.86)$ & \\
\hline Age & mean (SD) & $55(16)$ & $53(18)$ & $1.00(1.00,1.00)^{* *}$ & 0.9970 \\
\hline Charlson Comorbidity Index & mean (SD) & $2(1)$ & $1(2)$ & $0.72(0.70,0.75)^{* * *}$ & $<.0001$ \\
\hline
\end{tabular}

*Frequencies are calculated using all eligible hospital separations $(\mathrm{N}=49,721)$. Odds ratios are calculated for hospital separations with complete patient characteristic data $(N=47,803)$

**Odds ratio is the increase in odds for each additional year of age. ${ }^{* *}$ Odds ratio is the increase in odds for each one unit increase on Charlson Comorbidity Index

Data source: 48 Hour Follow Up Program Register. Study period: May 2009 to December 2014 [17] 
Table 2 Hospital separations of Aboriginal patients that resulted in an adverse event within 28 days of discharge, by whether the patient received 48 Hour Follow Up $(n=49,721)$

\begin{tabular}{llll}
\hline Variable & $\begin{array}{l}\text { Number of events among separations that did } \\
\text { not receive 48 Hour Follow Up N (\%) } \\
(n=41,252)\end{array}$ & $\begin{array}{l}\text { Number of events among separations that } \\
\text { received 48 Hour Follow Up N (\%) } \\
(n=8469)\end{array}$ & $\begin{array}{l}\text { Total number with } \\
\text { event (\% of total sample) }\end{array}$ \\
\hline $\begin{array}{l}\text { Unplanned hospital } \\
\text { readmission within }\end{array}$ & $3119(7.6 \%)$ & $455(5.4 \%)$ & $3574(7.2 \% ; 95 \% \mathrm{Cl} 7.0,7.4)$ \\
28 days & & $75(0.9 \%)$ & $535(1.1 \% ; 95 \% \mathrm{Cl} 0.98,1.2)$ \\
$\begin{array}{l}\text { Mortality within } 28 \text { days } \\
\text { Unplanned ED }\end{array}$ & $960(1.1 \%)$ & $1745(21 \%)$ & $11,280(22.7,95 \% \mathrm{Cl} 22.3,23.0)$ \\
$\begin{array}{l}\text { presentation } \\
\text { within } 28 \text { days }\end{array}$ & $9535(23 \%)$ & $1810(21 \%)$ & $11,946(24 \% ; 95 \% \mathrm{Cl} 23.6,24.4)$ \\
At least 1 adverse event & $10,136(25 \%)$ & & \\
\hline
\end{tabular}

Data source: 48 Hour Follow Up Program Register. Study period: May 2009 to December 2014 [17]

Rates of adverse events by receipt of $\mathbf{4 8}$ Hour Follow Up Results of multivariable logistic regression modelling of adverse events associated with receipt of 48 Hour Follow Up, which are adjusted for all variables given in the table, are shown in Table 3. After adjusting for potential confounders, there was no statistically significant association between receipt of 48 Hour Follow Up and unplanned readmission or mortality within 28 days of discharge.

After adjusting for potential confounders, the odds of an unplanned ED presentation within 28 days were significantly lower for separations where the patient received 48 Hour Follow Up compared with those that did not receive 48 Hour Follow $\mathrm{Up}(\mathrm{OR}=0.92$; 95\% CI: 0.85, $0.99 ; P=0.0312)$. The adjusted odds of at least one adverse event for those that received 48 Hour Follow Up was also significantly lower $(\mathrm{OR}=0.91 ; 95 \% \mathrm{CI}$ : $0.85,0$. 98; $P=0.0136)$ compared with separations that did not receive 48 Hour Follow Up.

\section{Discussion}

To the best of our knowledge, this is the first study to examine the effectiveness of TFU for recently discharged Aboriginal people with chronic disease. While there was no evidence of an effect of the 48 Hour Follow Up program on unplanned readmissions or mortality within 28 days of discharge, receipt of 48 Hour Follow Up was significantly associated with both fewer unplanned ED presentations and at least one adverse event within 28 days of discharge.

There are a number of potential reasons for the lack of a significant reduction in unplanned hospital readmissions. Firstly, the target population for 48 Hour Follow Up (i.e. all Aboriginal people aged 15 years and older, with a specified chronic disease and who have been discharged from hospital) is broad, and there is no state-wide protocol for prioritizing the order in which patients receive 48 Hour Follow Up. Melton and colleagues conducted a randomised controlled trial among patients with gastrointestinal, heart, and lower respiratory diagnoses [19]. The intervention group received TFU within $24 \mathrm{~h}$ of discharge, and calls were prioritized so that patients with the greatest likelihood of readmission due to poorer health status were contacted first. A control group received TFU three days after discharge, and calls were not made in any health risk order. The prioritized treatment group had significantly fewer 30 day intent-to-treat readmissions (5.7\% vs $7.3 \%$; $p$ $<.05)$ compared with the non-prioritized control group [19]. This suggests the effectiveness of 48 Hour Follow Up may be enhanced by prioritizing 'high risk' patients for earlier follow up. However, there remain gaps in the evidence of what makes an effective TFU program. Mistiaen and Poot in their systematic review of TFU stress the need for further research to establish the ideal person to make the follow up call, the frequency and timing of calls, the content of the calls, and to identify the potential patient, health system and country differences in TFU interventions [6].

A second potential reason for the lack of a significant reduction in readmissions may be due to 48 Hour Follow Up being a standalone intervention. Although some LHDs have expanded the program to have additional components (e.g. in the localised model, some patients receive home visits), the centralised model delivers TFU as a standalone strategy. Hansen and colleagues comment on the merit of "bridging interventions" which combine pre- and post-discharge care to act as a "bridge" between hospital-, home- and community-based health care. [8] Studies conducted with other population groups have demonstrated the effectiveness of multi-component programs incorporating TFU with other intervention strategies such as discharge planning, patient education, home visits and transition coaching. [7, 8] For example, a non-randomised trial by Sales and colleagues amongst cardiac patients used trained volunteers to provide pre-discharge patient education and medication instructions and post-discharge TFU [20]. Compared with standard care, the intervention group had lower rates of 30-day readmissions [20]. Jayakody and colleagues in their systematic review of interventions utilising TFU amongst patients with chronic disease found all 10 included studies combined TFU with other components [9]. Although they report that the studies did not 
Table 3 Association between receipt of 48 Hour Follow Up and adverse events among Aboriginal patients: Logistic GEE models adjusting for variables associated with both receipt of 48 Hour Follow Up and the adverse event $(n=49,721)^{*}$

\begin{tabular}{|c|c|c|c|c|c|c|c|c|c|}
\hline \multirow[b]{2}{*}{ Variable } & \multirow[b]{2}{*}{ Category } & \multicolumn{2}{|l|}{$\begin{array}{l}\text { Unplanned } \\
\text { readmission }\end{array}$} & \multicolumn{2}{|l|}{ Mortality } & \multicolumn{2}{|l|}{ ED presentation } & \multicolumn{2}{|l|}{$\begin{array}{l}\text { At least } 1 \\
\text { adverse event }\end{array}$} \\
\hline & & OR $(95 \% \mathrm{Cl})$ & $P$-value & OR $(95 \% \mathrm{Cl})$ & $P$-value & OR $(95 \% \mathrm{Cl})$ & $P$-value & OR $(95 \% \mathrm{Cl})$ & $P$-value \\
\hline \multirow[t]{2}{*}{ Follow up } & Not followed up & reference & 0.1352 & reference & 0.4760 & reference & 0.0312 & reference & 0.0136 \\
\hline & Followed up & $0.84(0.66,1.06)$ & & $0.91(0.69,1.19)$ & & $0.92(0.85,0.99)$ & & $0.91(0.85,0.98)$ & \\
\hline \multirow[t]{4}{*}{ Care type } & Centralised & & & & & reference & $<.0001$ & reference & $<.0001$ \\
\hline & Shared care & & & & & $1.00(0.91,1.10)$ & & $1.02(0.93,1.11)$ & \\
\hline & Localised & & & & & $0.77(0.72,0.83)$ & & $0.81(0.76,0.87)$ & \\
\hline & AMS-contracted & & & & & $1.01(0.76,1.33)$ & & $0.94(0.72,1.24)$ & \\
\hline \multirow[t]{6}{*}{ Year } & 2009 & & & reference & 0.0003 & reference & $<.0001$ & reference & $<.0001$ \\
\hline & 2010 & & & $1.19(0.81,1.73)$ & & $1.10(0.99,1.23)$ & & $1.06(0.95,1.18)$ & \\
\hline & 2011 & & & $1.40(0.96,2.05)$ & & $1.24(1.11,1.38)$ & & $1.20(1.08,1.33)$ & \\
\hline & 2012 & & & $1.50(1.06,2.12)$ & & $1.29(1.15,1.43)$ & & $1.22(1.10,1.35)$ & \\
\hline & 2013 & & & $1.50(1.08,2.08)$ & & $1.32(1.19,1.46)$ & & $1.24(1.12,1.37)$ & \\
\hline & 2014 & & & $0.75(0.50,1.12)$ & & $1.21(1.07,1.36)$ & & $1.12(1.00,1.26)$ & \\
\hline \multirow[t]{5}{*}{ IRSD quintile } & $\begin{array}{l}\text { 1st quintile - least } \\
\text { disadvantaged }\end{array}$ & & . & & & reference & $<.0001$ & reference & 0.0005 \\
\hline & 2nd quintile & & & & & $0.91(0.82,1.00)$ & & $0.92(0.83,1.01)$ & \\
\hline & 3rd quintile & & & & & $0.99(0.89,1.09)$ & & $0.99(0.91,1.09)$ & \\
\hline & 4th quintile & & & & & $0.82(0.74,0.90)$ & & $0.85(0.77,0.94)$ & \\
\hline & $\begin{array}{l}\text { 5th quintile - } \\
\text { most } \\
\text { disadvantaged }\end{array}$ & & & & & $0.80(0.72,0.89)$ & & $0.85(0.77,0.94)$ & \\
\hline \multirow[t]{2}{*}{ Length of stay } & 1 day or less & & & reference & $<.0001$ & reference & 0.0007 & reference & $<.0001$ \\
\hline & More than 1 day & & & $1.93(1.53,2.42)$ & & $1.11(1.04,1.17)$ & & $1.13(1.06,1.19)$ & \\
\hline \multirow{2}{*}{$\begin{array}{l}\text { No. of additional } \\
\text { diagnoses }\end{array}$} & Less than 2 & reference & 0.2646 & reference & 0.1804 & reference & 0.0187 & reference & 0.0870 \\
\hline & 2 or more & $1.13(0.91,1.40)$ & & $1.240 .91,1.68)$ & & $1.09(1.01,1.17)$ & & $1.06(0.99,1.14)$ & \\
\hline $\begin{array}{l}\text { Charlson } \\
\text { Comorbidity } \\
\text { Index }\end{array}$ & & $1.11(1.06,1.17)$ & $<.0001$ & $1.46(1.40,1.53)$ & $<.0001$ & $1.08(1.06,1.11)$ & $<.0001$ & $1.10(1.08,1.13)$ & $<.0001$ \\
\hline
\end{tabular}

*Odds ratios are from the logistic regression GEE model and are adjusted for all variables given in the table

Data source: 48 Hour Follow Up Program Register. Study period: May 2009 to December 2014 [17]

uniformly demonstrate significant reductions in readmission rates, the findings did suggest some merit in combining TFU with pre-discharge interventions such as discharge planning and patient education. Therefore standalone TFU interventions such as the 48 Hour Follow Up program may be strengthened by being combined with other interventions.

The association of 48 Hour Follow Up with both reductions in unplanned ED presentations and at least one adverse event is encouraging. Our results are similar to an intervention conducted in the United States by Dudas and colleagues who randomly assigned general medicine patients to receive a telephone call from a pharmacist within two days of discharge [21]. The study resulted in a significant reduction in unplanned ED presentations but not readmissions within 30 days. Although the patient group and person making the call were different to the 48 Hour Follow Up program, the call timing and content were similar. TFU calls may improve patients' ability to self-manage their health issues and/or connect with community-based health services such as their general practitioner, rather than presenting to the ED. A key strength of TFU is its relative ease of implementation: it is less labour intensive than interventions such as home visits, is low cost, and is scalable to reach large populations $[6,22]$. Although 48 Hour Follow Up did not significantly reduce unplanned hospital readmissions, the findings related to reduced unplanned ED presentations and adverse events suggest the program has some health benefits for patients. Future research may seek to identify which program characteristics (e.g. inclusion of home visits, whether the person conducting the 48 Hour Follow Up call is an Aboriginal person) influence the impact of 48 Hour Follow Up. In addition, the potential 
economic and health system benefits of reduced hospital utilization are worthy of further study [21].

Our study found that patients with more comorbidities (i.e. a higher Charlson Comorbidity Index and those with two or more chronic diseases) had lower odds of receiving 48 Hour Follow Up. This was an unexpected finding as there is no prioritisation of patients for 48 Hour Follow Up, and therefore we would expect there to be no association between comorbidity and receipt of follow up. A similar "treatment-risk paradox" [23] was observed by Wong and colleagues, who found that among patients presenting to Canadian EDs with chest pain, those with more comorbidities were less likely to receive physician follow-up after discharge [24]. One possible explanation is that 48 Hour Follow Up staff may refer patients with comorbidities directly to other chronic disease management programs more tailored to supporting patients with complex needs, without conducting the 48 Hour Follow Up call; however 48 Hour Follow Up program staff interviewed in our process evaluation did not indicate that this was the case [17]. Another possible explanation is that patients with comorbidities may be less likely to answer or accept the 48 Hour Follow Up call, for example because they are already linked with other community-based health services and do not feel a need for additional support. Regardless of the reason why patients with comorbidities were less likely to receive 48 Hour Follow Up, this finding highlights the importance of prioritising high-risk patients to receive 48 Hour Follow Up, and more broadly the importance of integration of services to ensure patients with comorbidities do not fall through the net of service delivery.

\section{Limitations}

This evaluation had a number of limitations. Firstly, an experimental design such as a randomised controlled trial would have provided the most robust information about effectiveness. However, randomized designs are not always feasible for population-level interventions [25]. In this case it was not possible given the program has been implemented state-wide for several years, aims to reach the entire population of Aboriginal people with chronic disease, and has variability in implementation across LHDs. A nonrandomised cohort design was considered the most feasible approach to balance the tension between scientific rigour and the practicalities of evaluating an established state-wide government program. Secondly, the study relied on routinely-collected health data, rather than data collected for research purposes. Some limitations of routinelycollected data include the possibility of underreporting of Aboriginality in hospital data [14], and limited capacity to adjust for confounding variables. For example socioeconomic status, a strongly confounding variable in this study, was measured based on patients' postcode, and therefore may not have been an accurate measure of individuals' socio-economic status. Thirdly, as the analysis explored one primary and three secondary outcomes, there is an elevated risk of declaring spuriously positive associations.

\section{Conclusions}

The effectiveness of TFU in reducing adverse events has not previously been shown for Aboriginal people. Such findings help address the paucity of published research describing the effectiveness of policies and programs that target Aboriginal people. Our study found that the 48 Hour Follow Up program was not associated with reduced hospital readmissions or mortality within 28 days of hospital discharge among Aboriginal people with a chronic disease. However, receipt of 48 Hour Follow Up was associated with both a significant reduction in unplanned ED presentations and at least one adverse event (hospital readmission, ED presentation or mortality) within 28 days of discharge, suggesting there may be some merit in providing postdischarge TFU to Aboriginal people with chronic disease.

\section{Additional Files}

Additional file 1: ICD-10 codes used for $48 \mathrm{~h}$ follow up (Principle or an additional diagnosis). A list of all ICD-10 codes for chronic diseases meeting the eligibility cireria for the 48 Hour Follow Up program. (DOCX 22 kb)

Additional file 2: Sensitivity analysis results. Results of sensitivity analyses: factors associated with being followed up either within or outside $48 \mathrm{~h}$; summary of the number of admissions that resulted in an adverse event by whether or not they received Follow Up; and Crude (Unadjusted) Models for "Not followed up" compared to "Followed up within 48 hours". (DOCX 29 kb)

\section{Abbreviations}

AMS: Aboriginal Medical Service; APDC: NSW Admitted Patient Data Collection; CDMP: NSW Chronic Disease Management Program;

Cl: Confidence interval; ED: Emergency department; EDDC: NSW Emergency Department Data Collection; IRSD: Index of Relative Socio-economic Disadvantage; LHD: Local health districts; NSW: New South Wales; OR: Odds ratio; RBDM: NSW Register of Births, Deaths and Marriages; SD: Standard deviation; TFU: Telephone follow up

\section{Acknowledgements}

We would like to acknowledge the traditional custodians of NSW, Australia, the Aboriginal people and pay our respects to the Elders past, present and future. We would also like to acknowledge the many NSW Health staff who have supported the implementation, monitoring and evaluation of the 48 Hour Follow Up program and the 48 Hour Follow Up Program Evaluation Advisory Committee members for their advice and guidance throughout the study design and implementation.

\section{Funding}

This study was funded by NSW Health.

\section{Availability of data and materials}

The data that support the findings of this study (48 Hour Follow Up Register) are available from NSW Health but restrictions apply to the availability of these data and so are not publicly available. Access to the data is available by application to the data custodians, NSW Health.

\section{Authors' contributions}

AJ and EP provided equal contributions as first authors. RSF, AM, EP, J Bryant, $M C, L M, M T$, J Bunfield and AC contributed to the design of the study. AJ and EP drafted the manuscript. CO conducted the analysis with data 
verification support from EP and $A C$. ES, $K H, E P$ and $A C$ contributed to data collation. All authors contributed to the interpretation of findings, and have read and approved the final manuscript.

\section{Ethics approval and consent to participate}

This study received full ethical approval from the Aboriginal Health and Medical Research Council Ethics Committee (967/13) and the University of Newcastle Research Ethics Committee (H-2013-0381).

\section{Competing interests}

AJ, EP, ES, AC, LM, KH, J Bunfield, MT and AM acknowledge a competing interest in that they are employed or affiliated with NSW Health which is the funding body for this study.

\section{Publisher's Note}

Springer Nature remains neutral with regard to jurisdictional claims in published maps and institutional affiliations.

\section{Author details}

'Health Behaviour Research Collaborative, School of Medicine and Public Health, Faculty of Health and Medicine, University of Newcastle, Callaghan, NSW 2308, Australia. ${ }^{2}$ Priority Research Centre for Health Behaviour, University of Newcastle, Callaghan 2308, NSW, Australia. ${ }^{3}$ Hunter Medical Research Institute, New Lambton Heights 2305, NSW, Australia. ${ }^{4}$ Evidence and Evaluation, Centre for Epidemiology and Evidence, NSW Ministry of Health LMB 961, North Sydney, Sydney, NSW 2059, Australia. ${ }^{5}$ School of Medicine and Public Health, University of Newcastle, Callaghan, NSW 2308, Australia. ${ }^{6}$ CREDITSS_Clinical Research Design, Information Technology and Statistical Support Unit, Hunter Medical Research Institute, HMRI Building, New Lambton Heights 2305, NSW, Australia. ${ }^{7}$ NSW Agency for Clinical Innovation, Level 4, Sage Building, 67 Albert Ave, Chatswood, Sydney, NSW 2067, Australia. ${ }^{8}$ School of Public Health and Community Medicine, University of NSW, Sydney 2033, Australia. ${ }^{9}$ Centre for Aboriginal Health, NSW Ministry of Health LMB 961, North Sydney, Sydney, NSW 2059, Australia. ${ }^{10}$ Sydney Medical School, University of Sydney, Edward Ford Building A27, The University of Sydney, Sydney, NSW 2006, Australia.

\section{Received: 7 September 2017 Accepted: 8 May 2018}

Published online: 18 May 2018

\section{References}

1. Cooke M, Mitrou F, Lawrence D, Guimond E, Beavon D. Indigenous wellbeing in four countries: an application of the UNDP'S human development index to indigenous peoples in Australia, Canada, New Zealand, and the United States. BMC Int Health Hum Rights. 2007:7:9.

2. Australian Bureau of Statistics. Life tables for aboriginal and Torres Strait islander Australians. In: 2010-2012 catalogue number 3302.0.55, vol. 003. Canberra: ABS; 2013.

3. Australian Institute of Health and Welfare. The health and welfare of Australia's Aboirginal and Torres Strait islander people: an overview. In: Cat No. IHW, vol. 42. Canberra: AlHW; 2011.

4. Vos T, Barker B, Begg S, Stanley L, Lopez AD. Burden of disease and injury in aboriginal and Torres Strait islander peoples: the indigenous health gap. Int J Epidemiol. 2009:38:470-7.

5. Centre for Epidemiology and Evidence. The health of aboriginal people of NSW: report of the chief health officer. Sydney: NSW Ministry of Health; 2012

6. Mistiaen P, Poot E. Telephone follow-up, initiated by a hospital-based health professional, for postdischarge problems in patients discharged from hospital to home. In: Cochrane Database Syst. Rev. England: Wiley; 2006.

7. Takeda A, Taylor SJ, Taylor RS, Khan F, Krum H, Underwood M. Clinical service organisation for heart failure. Cochrane Database Syst Rev. 2012;9: CD002752.

8. Hansen LO, Young RS, Hinami K, Leung A, Williams MV. Interventions to reduce 30-day rehospitalization: a systematic review. Ann Intern Med. 2011; 155:520-8.

9. Jayakody A, Bryant J, Carey M, Hobden B, Dodd N, Sanson-Fisher R. Effectiveness of interventions utilising telephone follow up in reducing hospital readmission within 30 days for individuals with chronic disease: a systematic review. BMC Health Serv Res. 2016;16:403.
10. Milat AJ, Bauman AE, Redman S, Curac N. Public health research outputs from efficacy to dissemination: a bibliometric analysis. BMC Public Health 2011;11:934

11. Wolfenden L, Milat AJ, Lecathelinais C, Sanson-Fisher RW, Carey ML, Bryant J, Waller A, Wiggers J, Clinton-CHarg T, Lin Yoong S. What is generated and what is used: a description of public health research output and citation. Eur J Pub Health. 2016;26:523-5.

12. NSW Government: Public Health Act 2010 No 127. NSW Australia. Accessed 12/01/2017: http://www.legislation.nsw.gov.au/inforce/e20f1d11-6a0d-ec9afe79-d31ae57c52c3/2010-127.pdf; 2010.

13. Centre for Health Record Linkage: [http://www.cherel.org.au].

14. Bentley JP, Taylor LK, Brandt PG. Reporting of aboriginal and Torres Strait islander peoples on the NSW admitted patient data collection: the 2010 data quality survey. New South Wales Public Health Bulletin. 2012;23:17-20.

15. Charlson ME, Pompei $P$, Ales KL, Mackenzie CR. A new method of classifying prognostic comorbidity in longitudinal studies: development and validation. J Chronic Dis. 1987:40:373-83.

16. Australian Bureau of Statistics. IRSD. Census of population and housing: socio-economic indexes for areas (SEIFA). ABS, Australia. Access. 2016;1:2011.

17. University of Newcastle, Centre for Epidemiology and Evidence, NSW Agency for Clinical Innovation: 48 Hour Follow Up Evaluation: Final Report. Centre for Epidemiology and Evidence. NSW Ministry of Health. Available at: http://www.health.nsw.gov.au/research/Documents/48-hour-evaluationreport.pdf; 2016.

18. SAS Institute Inc. SAS version 9.1.3 [software]. Cary. In: North Carolina: SAS 2003.

19. Melton LD, Foreman C, Scott E, McGinnis M, Cousins M. Prioritized post discharge telephonic outreach reduces hospital readmissions for select high-risk patients. Am J Manag Care. 2012;18:838-44.

20. Sales VL, Ashraf MS, Lella LK, Huang J, Bhumireddy G, Lefkowitz L, Feinstein M, Kamal M, Caesar R, Cusick E, et al. Utilization of trained volunteers decreases 30-day readmissions for heart failure.[Republished from J Card Fail. 2013 Dec 19(12):842-50; PMID: 24331204]. J Card Fail. 2014;20(377):e315-23.

21. Dudas V, Bookwalter T, Kerr KM, Pantilat SZ. The impact of follow-up telephone calls to patients after hospitalization. Am J Med. 2001;111:26S-30S.

22. Bahr SJ, Solverson S, Schlidt A, Hack D, Smith JL, Ryan P. Integrated literature review of postdischarge telephone calls. West J Nurs Res. 2014;36: 84-104.

23. Ko DT, Mamdani M, Alter DA. Lipid-lowering therapy with statins in highrisk elderly patients: the treatment-risk paradox. JAMA. 2004;291:1864-70.

24. Wong MKY, Wang JT, Czarnecki A, Koh M, Tu JV, Schull MJ, Wijeysundera HC, Lau C, Ko DT. Factors associated with physician follow-up among patients with chest pain discharged from the emergency department. CMAJ. 2015:187:E160-8.

25. Sanson-Fisher RW, Bonevski B, Green LW, D'Este C. Limitations of the randomized controlled trial in evaluating population-based health interventions. Am J Prev Med. 2007;33:155-61.
- fast, convenient online submission

- thorough peer review by experienced researchers in your field

- rapid publication on acceptance

- support for research data, including large and complex data types

- gold Open Access which fosters wider collaboration and increased citations

- maximum visibility for your research: over $100 \mathrm{M}$ website views per year

At BMC, research is always in progress.

Learn more biomedcentral.com/submissions 